\title{
PENGARUH PENGETAHUAN KOPERASI, MOTIVASI BERKOPERASI DAN PELAYANAN KOPERASI TERHADAP MINAT MENJADI ANGGOTA KOPERASI MAHASISWA
}

\author{
Yohana Jaya \\ e-mail: hanajaya97@gmail.com \\ Rusno \\ e-mail: rusno@unikama.ac.id \\ Auliana Farrabanie Al Arsy \\ e-mail:auliana@unikama.ac.id
}

(Program Studi Pendidikan Ekonomi, Fakultas Ekonomika dan Bisnis, Universitas Kanjuruhan, Malang)

\begin{abstract}
This study uses a population of 335 students of Universitas Kanjuruhan Malang who entered the cooperative in 2017-2018 and then the sampling technique was taken 25\% of the population using proportional random sampling. The results of this study indicate that: 1) cooperative knowledge, cooperative motivation, cooperative services have a joint effect on the interests of students becoming members of student cooperatives in Universitas Kanjuruhan Malang, 2) cooperative knowledge has a positive and significant effect on the interests of students becoming members of student cooperatives, 3 ) motivation to operate positively and significantly influence the interests of students to become members of student cooperatives, 4) cooperative services have a positive and significant effect on the interests of students to become members of student cooperatives.
\end{abstract}

Keywords : Cooperative Knowledge, Cooperative Motivation, Cooperative Services, Interest in Becoming a Cooperative Member.

Abstrak: Penelitian ini menggunakan populasi sebanyak 335 mahasiswa Universitas Kanjuruhan Malang yang masuk koperasi pada tahun 2017- 2018 kemudian teknik pengambilan sampelnya diambil 25\% dari populasi yang ada dengan menggunakan propotional random sampling. Hasil penelitian ini menunjukan bahwa: 1) pengetahuan koperasi, motivasi koperasi, pelayanan koperasi berpengaruh secara bersama-sama terhadap minat mahasiswa menjadi anggota koperasi mahasiswa Universitas Kanjuruhan Malang, 2) pengetahuan koperasi berpengaruh secara positif dan signifikan terhadap minat Mahasiswa menjadi anggota koperasi mahasiswa, 3) motivasi berkoperasi berpengaruh secara positif dan signifikan terhadap minat mahasiswa menjadi anggota koperasi mahasiswa, 4) pelayanan koperasi berpengaruh secara positif dan signifikan terhadap minat mahasiswa menjadi anggota koperasi mahasiswa.

Kata kunci : Pengetahuan Koperasi, Motivasi Berkoperasi, Pelayanan Koperasi, Minat Menjadi Anggota Koperasi. 


\section{PENDAHULUAN}

Indonesia merupakan Negara berkembang denga jumlah penduduk yang sangat besar. Banyaknya jumlah penduduk tersebut mengakibatkan banyak permasalah yang ditimbulkan, salah satunya kesejahteraan masyarakat. Upaya yang dapat melakasanakan untuk meralisasikan pemerataan kesejahteraan bagi masyarakat dapat ditemuh berbagai cara, salah satunya adalah berkoperasi. Koperasi merupakan badan usaha yang beranggotakan orang yang dikelola berdasarkan asas kekeluargaan.Tujuan koperasi adalah memajukan kesejahteraan anggota khususnya dan masyarakat pada umumnya. Koperasi sebagai organisasi gerakan ekonomi rakyat, tidak hanya pada masyarakat umum saja tetapi menyentuh ranah mahasiswa sehingga perkembangan koperasi mahasiswa bersinergi dengan jalanya koperasi pada umumnya. Berkembang atau tidaknya sebuah koperasi mahasiswa akan dipengaruhi oleh banyaknya anggota yang berminat untuk menjadi anggota dikoperasi. Semakin banyak anggota yang aktif dikoperasi maka semakin banyak pula peluang koperasi untuk berkembang kearah yang lebih maju sehingga bersaing dengan baddan usaha lain. Sejauh ini mahasiswa Universitas Kanjuruhan Malang yang menjadi anggota koperasi pada tahun tahun 2017-2018 sebanyak 335 mahasiswa.

Pengetahuan berperan penting dalam berkoperasi. Pengetahuan adalah segala sesuatu yang diketahui. Koperasi mahasiswa Universitas Kanjuruhan Malang semua anggota terdiri dari beberapa fakultas yaitu FST, FBS, FEB, FKIP, FH dan Peternakan. Sedangkan dilapangan mayoritas anggotanya adalah mahasiswa FEB padhal tujuan terbentuknya koperasi mahasiswa ini selain sebagai tempat praktik mahasiswa ekonomi, juga koperasi mahasiswa ini sangat penting untuk dimanfaat oleh mahasiswa pada umumnya agar mendapatkan pengetahuan dalam dunia kerja nantinya. Dalam koperasi motivasi yang dibutuhkan dari anggota adalah motivasi dalam menjalankan hak dan kewajibannya. Angggota dapat membeli barangdari koperasi dan dapat menyimpan serta meminjam melalui koperasi. Hal tersebut bertujuan agar usaha koperasi berjalan dengan lancar. Koperasi mahasiswa Universitas Kanjuruhan Malang banyak yang ikut menjadi anggota koperasi tetapi tidak aktif dalam kegiatan koperasi. Berdasarkan observasi hal tersebut karena beberapa faktor seperti tuntutan dosen dan juga teman yang mengajak.

Kepuasan mahasiswa terhadap pelayanan dari pengurus dapat mendorong minat mahasiswa untuk ikut bergabung menjadi anggota koperasi mahasiswa, apabila pelayanan koperasi mahasiswa yang diterima atau dirasakan sesuai denga yang diharapakan, maka dipersepsikan baik dan memuaskan. Pelayanan kkoperasi mahasiswa Universitas Kanjuruhan Malang cucup baik tapi belum mencukupi kebutuhan lainnya yang diperlukan seperti lahan parker dan AC dalam ruangan swalayan membuat orang kurang nyaman. Adapun tujuan dari penelitian ini berdasarkan latarbelakang dan rumusan masalah adalah untuk mengetahui apakah ada pengaruh yang positif dan signifikan pengetahuan koperasi, motivasi berkoperasi dan pelayanan koperasi terhadap minat menjadi anggota koperasi.

\section{TINJAUAN PUSTAKA}

Menurut Slameto (2013:57) minat adalah kecendrungan yang tetap untuk memperhatikan atau mengenang beberapa kegiatan. Menurut Syah (2012:551) minat seseorang timbul karena dua faktor yaitu:

a) Faktor internal

Perasaan ,Perhatian, Pengalaman, Cita-cita, Rasa ingin tahu

b) Faktor ekternal

Pengaruh lingkungan keluarga, Lingkungan kampus, Lingkungan masyarakat. 
Berdasarkan teori Budiningsih (dalam Zulfanedhi 2011:25) pengetahuan sebagai konstruksi kognitif seseorang terhadap obyek, pengalaman maupun lingkungannya. Sebagai indikatornya sebagai berikut:
a. Pemahaman tentang koperasi
b. Manfaat koperasi
c. Hak dan kewajiban koperasi
d. Prinsip koperasi

Menurut Uno (2014:9) motivasi adalah suatu dorongan yang timbul oleh adanya rangsangan dari dalam maupun dari luar sehingga seorang berkeinginan untuk mengadakan perubahan tingkah laku/aktivitas tertentu lebih baik dari keadaan sebelumnya. Menurut Uno (2014:112) Motivasi memiliki indikator sebagai berikut:
a. Tanggung jawab
b. Prestasi
c. Pengembangan diri
d. Kemandirian

Menurut Santi (dalam Dhea Ayu, 2015:29-30) pelayanan adalah kegiatan yang dilakukan oleh seseorang atau kelompok orang dengan landas faktor material malalui system, prosedur dan metode tertentu dalam rangka memenuhi kebutuhan orang lain sesuai denga hak dan kewajibannya. Menurut Joesron (2005:15-16) mengatakan bahwa terdapat lima dimensi untuk mengukur kualitas pelayanan yaitu sebagai berikut:
a. Reability (keandalan)
b. Responsiveness (daya tanggap)
c. Assurance (keterjaminan)
d. Emphaty (empati)

Penelitian ini melampirkan beberapa penelitian terdahulu yang berkaitan dengan judul penelitian ini yaitu:

1. Penelitian ini dilakukan oleh Zulfanedhi, 2016. Tentang pengaruh pengetahuan perkoperasian dan persepsi tentang koperasi terhadap minatmahasiswa pendidikan ekonomi menjadi anggota koperasi mahasiswa UNY.

2. Penelitian ini dilakukan oleh Fardiansyah, 2011. Tentang pengaruh pendidikan perkoperasian,persepsi tentang koperasi dan motivasi berkoperasi terhadap minat masyarakat menjadi anggota KUD darma tani kecamatan boja kabupaten Kendal.

3. Penelitian ini dilakukan oleh Ariyanto 2013. Tentang pengaruh motivasi berkoperasi dan pelayanan koperasi terhadap minat mahasiswa menjadi pengurus koperasi mahasiswa (kopma) Universitas Muhammadiyah Purworejo.

4. Penelitian ini dilakukan oleh Handayani Noor,2015. Tentang pengaruh pengetahuan perkoperasian, motivasi berkoperasi dan kualitas pelayanan terhadap partisipasi anggota koperasi serba usaha (KSU) padurenan jaya gebog kabupaten kudus.

5. Penelitian iini dilakukan oleh Mario Franco, 2018. Tentang Cooperation process: what motivates individuals to participate in a cooperative?. Dari analisis wawancara 37 variabel yang memotivasi anggota untuk berpartisipasi dalam koperasi diidentifikasikasi, dengan ini dikelompokan berdasarkan kesamaan mereka dalam 5 kategori: 1) pengaruh eksternal, 2) karakteristik koperasi, 3) social psikologis, 4) hubungan, 5) manfaat.

\section{METODE}

Jenis penelitian ini termasuk penelitian expost facto yang mengkaji pengaruh antara variabel. Jenis penelitian ini menggunakan pendekatan kuatitatif, karena data dalam diwujudkan dalam bentuk angka dan dianalisis menggunakan analisis statistic dibantu dengan menggunakan SPSS versi 
16.00 for a windows. Penelitian ini dirancang untuk mengetahui berapa besar pengaruh variabel indenpenden terhadap variabel dependen.

Populasi dari penelitian adalah mahasiswa Universitas Kanjuruhan Malang yang masuk koperasi pada tahun 2017-2018 sebanyak 335 mahasiswa. Penelitian ini menggunakan teknik proportional random sampling. Proportional random sampling adalah teknik pengambilan sampel secara acak tanpa mempertimbangkan tingkatan-tingkatan dalam populasi (Arikunto,2010:134). Pengambilan sampel dalam penelitian ini dari populasi diambil 25\% untuk dijadikan sampel dengan jumlah 84 orang anggota koperasi yang akan diteliti. Sampel 84 mahasiswa ini diambil secara acak dari beberapa fakultas yaitu fakultas keguruan dan ilmu pendidikan, fakultas bahasa dan sastra, fakultas sains dan teknologi, fakultas ekonomika dan bisnis, fakultas pada mahasiswa Universitas Kanjuruhan Malang yang terletak di jl. S.Supriadi No.48 malang. Instrument penelitian menggunakan angket sebagai alat ukur dan dilakukan uji validitas dan reliabilitas dari hasil jawaban angket yang dipakai. Teknik pengumpulan data menggunakan angket atau kuesioner dan dokumentasi. Analisis data dalam penelitian ini menggunakan perhitungan statistic. Seperti uji asumsi klasik dan analisis regresi linear berganda. Pengujian hipotesis penelitian ini juga adalah $\mathrm{R}^{2}$ (koefisien determinasi), uji f secara simultan dan uji t secara parsial

\section{PEMBAHASAN}

Deskripsi hasil penelitian yang diperoleh dari hasil pengumpulan data dengan instrument penelitian skala likert. Penelitian ini mengambarkan dari masing-masing variabel penelitian yaitu Pengetahuan Koperasi, Kotivasi Berkoperasi, Pelayanan Koperasi dan Minat Menjadi Anggota Koperasi Mahasiswa Universitas Kanjuruhan Malang. Deskripsi data yang disajikan mencakup mean, median, standart deviation, variance, skor minimum dan maksimum. Pada analisis data pada uji asumsi klasik memperoleh hasil yaitu di uji normalitas regresi telah memenuhi persyaratan normalitas, uji multikolinearitas memperoleh hasil tidak ada gejala multikolinearitas dan dinyatakan normal karena nilai VIF nya lebih kecil dari 5, pada uji heteroskedastitas memperoleh hasil Tidak terjadi Heterokedastisitas karena diagram pencar residual tidak membentuk pola tertentu dan pada uji autokorelasi memperoleh hasil tidak terjadi autokorelasi, atau model regresi memenuhi persyaratan asumsi klasik tentang autokorelasi karena nilai signifikannya lebih kecil dari 0.05

Berdasarkan hasil penelitian statistic dengan bantuan SPSS 16.00 for windows pada pengujian hipotesis diperoleh tabel model summary yang menunjukan uji F statistic. Adapun hasil uji F pada tabel berikut:

Tabel 1. Uji F (secara simultan)

\begin{tabular}{|l|l|l|l|l|l|}
\hline Model & $\begin{array}{l}\text { Sum of } \\
\text { Square }\end{array}$ & df & $\begin{array}{l}\text { Mean } \\
\text { Square }\end{array}$ & F & Sig. \\
\hline $\begin{array}{l}\text { Regresion } \\
\text { Residual } \\
\text { Total }\end{array}$ & 417.196 & 3 & 139.065 & 7.89 & .000 \\
& $\begin{array}{l}1409.507 \\
1826.702\end{array}$ & 80 & 17.619 & 3 & \\
\hline
\end{tabular}

a. Predictors: (constant),PELAYANAN KOPERASI (X3), PENGETAHUAN KOPERASI (X1), MOTIVASI BERKOPERASI (X2)

b. Dependent Variabel: MINAT MENJADI ANGGOTA KOPERASI (Y)

Berdasarkan tabel di atas hasil tes Anova diperoleh nilai F-hitung sebesar 7.893 dengan tingkat signifikan 0.000, karena tingkat signifikan lebih kecil dari 0.05 maka hasil penelitian ini menerima hipotesis penelitian $\mathrm{H} 1$ yaitu: ada pengaruh yang signifikan antara variabel pengetahuan koperasi, motivasi berkoperasi dan pelayanan koperasi terhadap minat menjadi anggota kopma. 
Berdasarkan hasil penelitian statistic dengan bantuan SPSS 16.00 for windows diperoleh tabel Berdasarkan hasil perhitungan statistik dengan bantuan computer melalui program SPSS Versi 16.00 for windows diperoleh tabel coefficients yang menunjukkan uji $t$ statistik. Uji $t$ digunakan untuk menguji signifikan pengaruh masing-masing dari variabel independen yang terdiri dari Pengetahuan Koperasi, Motivasi Berkoperasi dan pelayanan koperasi terhadap variabel dependen yaitu minat menjadi anggota kopma. Adapun hasil uji F pada tabel berikut:

Tabel 2. Uji t (secara parsial)

\begin{tabular}{|l|l|l|l|}
\hline Model & \multicolumn{1}{|c|}{$\mathrm{t}$} & Sig. & Keterangan \\
\hline (contant) & 4.235 & .000 & Signifikan \\
\hline X1 & 2.445 & .017 & Signifikan \\
\hline X2 & 3.188 & .002 & Signifikan \\
\hline X3 & 2.492 & .015 & signifikan \\
\hline
\end{tabular}

Sumber data: hasil olahan SPSS 16.00 for a windows

Berdasarkan tabel di atas nilai $t$ hitung untuk variabel pengetahuan koperasi (X1) sebesar 2.445 dengan tingkat signifikan sebesar 0.017 karena tingkat signifikan lebih kecil dari 0.05 maka variabel pengetahun koperasi (X1) berpengaruh terhadap minat menjadi anggota kopma (Y) sehingga diterima $\mathrm{H} 2$ diterima. Hipotesis penelitian untuk menguji hipotesis ketiga $(\mathrm{H} 3)$, nilai t hitung untuk variabel motivasi berkoperasi (X2) sebesar 3.188 dengan tingkat signifikan 0.002 karena tingkat signifikannya lebih kecil dari 0.05 maka variabel motivasi berkoperasi (X2) berpengaruh terhadap variabel minat menjadi anggota kopma $(\mathrm{Y})$ sehingga $\mathrm{H} 3$ diterima. Hipotesis penelitian untuk menguji hipotesis keempat (H4), nilai t hitung untuk variabel pelayanan koperasi (X3) sebesar 2.492 dengan tingkat signifikan sebesar 0.015 karena tingkat signifikannya lebih kecil dari 0.05 maka variabel pelayanan koperasi (X3) berpengaruh dengan variabel minat menjadi anggota kopma (Y) sehingga H4 diterima. Berikut adalah Pembahasan dari hasil penelitian yang dilakukan oleh peneliti, sebagai berikut:

Berdasarkan hasil penelitian bahwa pengetahuan koperasi, motivasi berkoperasi dan pelayanan koperasi secara bersama-sama berpengaruh positif terhadap minat menjadi anggota, denga kata lain bahwa pengetahuan koperasi , motivasi berkoperasi dan pelayanan koperasi memiliki pengaruh yang signifikan terhadap minat menjadi anggota kopma Universitas Kanjuruhan Malang. Dari hasil penelitian tentang pengetahuan koperasi, motivasi berkoperasi dan pelayanan koperasi pada kategori baik, dapat dilihat ketiga variabel yang mempunyai pengaruh terhadap minat menjadi anggota kopma Universitas Kanjuruhan Malang. Penelitan ini sejalan dengan penelitian yang dilakukan oleh Handayani Noor (2015) tentang Pengaruh Pengetahuan Koperasi, Motivasi Berkoperasi dan Kualitas Pelayanan Terhadap Partisipasi Anggota Koperasi Serba Usaha (KSU) padurenan jaya gebong Kabupaten Kudus. hasil penelitian menunjukan ada pengaruh secara simultan variabel independe terhadap variabel dependen.

Berdasarkan hasil penelitian dengan perhitungan secara parsial pengaruh pengetahuan koperasi terhadap minat mahasiswa menjadi anggota kopma Universitas Kanjuruhan Malang, menunjukan bahwa pengetahun koperasi berpengaruh secara signifikan terhadap minat mahasiswa menjadi anggota kopma. Dapat dilihat pada uji t diperoleh hasil thitung sebesar 2.445 dengan tingkat signifikan 0.017. Karena memperoleh tingkat signifikan lebih kecil dari 0.05 maka penelitian ini menunjukan bahwa terdapat pengaruh positif antara pengetahuan koperasi terhadap minat mahasiswa menjadi anggota kopma Universitas Kanjuruhan Malang. Hasil penelitian ini sejalan dengan penelitian yang dilakukan oleh Zulfanedhi (2016) yang menyatakan bahwa ada pengaruh yang signifikan secara parsial pengetahuan koperasi terhadap minat mahasiswa pendidikan ekonomi menjadi anggota kopma UNY. 
Berdasarkan hasil penelitian denga perhitungan secara parsial pengaruh motivasi berkoperasi terhadap minat mahasiswa menjadi anggota kopma Universitas Kanjuruhan Malang. Menunjukan bahwa motivasi brekoperasi berpengaruh secara signifikan terhadap minat mahasiswa menjadi anggota kopma. Dapat dilihat pada uji t diperoleh hasil thitung sebesar 3.188 dengan tingkat signifikan sebesar 0.002, karena memperoleh tingkat signifikan lebih kecil dari 0.05 maka penelitian ini terdapat pengaruh positif antara motivasi berkoperasi terhadap minat mahasiswa menjadi anggota kopma Universitas Kanjuruhan Malang. Penelitian ini sejalan dengan penelitian yang dilakukan oleh Fardiansyah (2011) yang menyatakan bahwa motivasi berkoperasi berpengaruh secara positif dan signifikan terhadap minat menjadi anggota KUD Darma Tani Kecamatan Boja Kabupaten Kendal.

Berdasarkan hasil perhitungan secara parsial pelayanan koperasi terhadap minat mahasiswa menjadi anggota kopma Universitas Kanjuruhan Malang. Dapat dilihat pada uji $t$ hitung yang memperoleh hasil t hitung sebesar 2.492 dengan tingkat signifikan sebesar 0.15. karena memperoleh tingkat signifikan lebih kecil dari dari 0.05 maka pnelitian ini terdapat pengaruh secara positif dan signifikan antara pelayanan koperasi terhadap minat mahasiswa menjadi anggota kopma Universitas Kanjuruhan Malang. Penelitian ini sejalan dengan penelitian yang dilakukan oleh Ariyanto (2013) yang menyatakan bahwa pelayanan koperasi berpengaruh secara positif dan signifikan terhadap minat menjadi pengurus kopma Universitas Muhammadiyah Purworejo.

\section{KESIMPULAN}

Berdasarkan hasil penelitian dan pembahasan yang telah di bahas, maka di tarik kesimpulan sebagai berikut: Berdasarkan hasil analisis Ada pengaruh yang signifikan secara simultan tentang pengetahuan koperasi, motivasi berkoperasi, dan pelayanan koperasi terhadap minat menjadi anggota Kopma Universitas Kanjuruhan Malang. Berdasarkan hasil analisis ada pengaruh yang signifikan secara parsial pengetahuan koperasi terhadap minat menjadi anggota Kopma Universitas Kanjuruhan Malang. Dengan demikian semakin luas pengetahuan koperasi seseorang maka semakin tinggi pula minat untuk ikut berkoperasi. Berdasarkan hasil analisis ada pengaruh yang signifikan secara parsial tentang motivasi berkoperasi terhadap minat menjadi anggota Kopma Universitas Kanjuruhan Malang. Dengan demikian semakin tinggi mahasiswa memiliki motivasi untuk berkoperasi maka semakin banyak pula mahasiswa yang memiliki minat untuk ikut berkoperasi. Ada pengaruh yang signifikan secara parsial tentang pelayanan koperasi terhadap Minat menjadi anggota Kopma Universitas Kanjuruhan Malang. Dengan demikian semakin baik pelayanan koperasi maka semakin banyak pula mahasiswa yang memiliki minat menjadi anggota koperasi.

Berdasarkan kesimpulan maka saran diberikan oleh peneliti yaitu: yang pertama Hasil penelitian ini dapat dijadikan sebagai dasar pengetahuan, bahan evaluasi sekaligus informasi yang berkaitan dengan pengaruh pengetahuan koperasi, motivasi berkoperasi dan pelayanan koperasi terhadap minat mahasiswa menjadi anggota kopma Universitas Kanjuruhan Malang. Berdasarkan hasil penelitian sebagaian besar pengetahuan koperasi mahasiswa Universitas Kanjuruhan Malang dikategorikan sedang. Oleh karena itu peneliti menyarankan agar anggota Kopma memberikan pelatihan tentang koperasi secara berkesinambungan, sehingga tidak hanya memiliki pengetahuan dasar saat diklat tetapi anggota akan memperluaskan pengetahuannya secara terus menerus. Selain itu adapun untuk menarik minat mahasiswa menjadi anggota Kopma dengan meningkatkan motivasi berkoperasi, Kopma sebaiknya memberikan reward bagi anggota Kopma dalam kegiatan perkoperasian sehingga anggota maupun mahasiswa makin termotivasi untuk minat menjadi anggota koperasi. Sedangkan untuk pelayanan diharapakan tetap konsisten dalam memberikan pelayanan yang baik dan terus melakukan inovasi baru dalam hal memperbaiki maupun meningkatkan kualitas pelayanan bagi anggota. Dan yang kedua untuk penelitian selanjutnya Dalam penelitiaan ini juga terdapat beberapa kekurangan yaitu dimana kontribusi secara simultan 
memperoleh nilai yang sangat rendah $22,8 \%$ pada variabel pengetahuan,motivasi berkoperasi dan pelayanan koperasi terhadap minat menjadi anggota kopma. Oleh karena itu sebaiknya untuk peneliti selanjut diharapkan untuk meneliti variabel yang tidak diteliti dalam penelitian ini seperti citra koperasi,persepsi tentang koperasi, pendidikan perkoperasian dan lain-lain.

\section{DAFTAR PUSTAKA}

Arikunto,Suharsimi. 2010. Prosedur penelitian suatu pendekatan praktik. Jakarta: Rineka Cipta

Ayu, Dhea. 2015. Tentang pengaruh pendidikan perkoperasian dan pelayanan koperasi terhadap partisipasi anggota pada koperasi simpan pinjam (KSP) Argo Sumbing Mandiri, Kecamatan Tembarak Kabupaten Temanggung. Skripsi. Pendidikan Ekonomi.

Defi Sellia Zulfanedhi, 2016. Tentang pengaruhpengetahuan perkoperasian dan persepsi tentang koperasi terhadap minat mahasiswan pendidikan ekonomi menjadi anggota kopma UNY. Jurnal. Pendidikan Ekonomi volume 5, nomor 2.

Khoridatul, Hidayah. 2017. pengaruh pengetahuan tentang koperasi, kualitas pelayanan dan motivasi berkoperasi terhadap minat menjadi anggota koperasi mahasiswa. Skripsi

Kusumantoro. 2010. Minat Mahasiswa Untuk Menjadi Anggota Koperasi Mahasiswa. Semarang. Jurnal Pendidikan Ekonomi Dinamika Pendidikan, Hal. 147-155

Mario. Franco. 2018. Cooperation Process: What Motivates Individuals To Participate In a Cooperative?. International jurnal. Management Practice,volume 11,Nomor 1

Revrisond Baswir. 2010. Koperasi indonesia. Yokyakarta: BPFE Yokyakarta

Sudarsono. 2005. Koperasi Dalam Teori Dan Praktik. Jakarta: Rineka Cipta

Subandi . 2013. Ekonomi Koperasi (teori dan praktik). Bandung: Alfabeta

Sugiyono,2011. Memahami penelitian kuantitafif. Bandung: Alfabeta

Sukardi. 2014. Metode Penelitian Pendidikan Kompetensi Dan Praktinya. Jakarta: Erlangga

Uno, Hamzah. 2014. Teori Motivasi dan Pengukurannya. Jakarta: Bumi Aksara.

Undang-Undang RI Nomor 25 Tahun 1992. Tentang Koperasi

Winardi, J. 2008. Motivasi: Pemotivasian dalam manajemen. Jakarta: Rajawali Press 